\title{
A Decision Tree Based Approach for Microgrid Islanding Detection
}

\author{
Riyasat Azim, Yongli Zhu, Hira Amna Saleem, \\ Kai Sun, Fangxing Li \\ University of Tennessee \\ Knoxville, TN, USA \\ mazim@vols.utk.edu, yzhu16@vols.utk.edu, \\ hiraamna@hotmail.com, kaisun@utk.edu, fli6@utk.edu
}

\author{
Di Shi, Ratnesh Sharma \\ NEC Labs America \\ Cupertino, CA, USA \\ dshi@nec-labs.com \\ ratnesh@nec-labs.com
}

\begin{abstract}
This paper proposes a passive islanding detection technique for microgrid. The proposed technique relies on capturing the underlying signatures of a wide variety of system events on critical system parameters through the utilization of pattern recognition tools for islanding detection in a microgrid. The proposed technique is tested on a microgrid model implemented on IEEE 13-node distribution feeder system under a wide variety of system operating states. Results from test case study have been analyzed to evaluate the effectiveness of the proposed method. Case study results indicate that the proposed method can detect islanding events with high accuracy and reliability.
\end{abstract}

Index Terms-Distributed generation, decision tree, islanding detection, microgrids.

\section{INTRODUCTION}

Interconnection of distributed generations (DGs) with area electric power systems (EPS) presents numerous benefits. However, DG integration introduces several technical issues which needs to be considered in system planning and operations. Inadvertent islanding is one of the prime concerns associated with DG interconnections. Islanding is defined in IEEE Std. 1547 as "A condition in which a portion of an area electric power system (EPS) is energized solely by one or more local EPSs through the associated points of common couplings (PCC) while that portion of the area EPS is electrically separated from rest of the area EPS". IEEE Std. 1547 recommends isolation of DG units within a maximum of 2 seconds in events of island formation in distribution networks and microgrids [1].

Islanding detection techniques are generally divided into three main categories, namely- active, passive and communication based techniques. Communication based islanding detection methods mainly use "transfer trip" or "power line signaling" in order to detect islanding conditions. These methods require extensive communications infrastructures and hence expensive. Active techniques rely upon perturb and observe methods. Although active methods have smaller non-detection zones (NDZ) compared to passive

This work was supported by NEC Laboratories America, Inc. techniques, they cause degradation of power quality and require complex control for the perturbation injections [2-3].

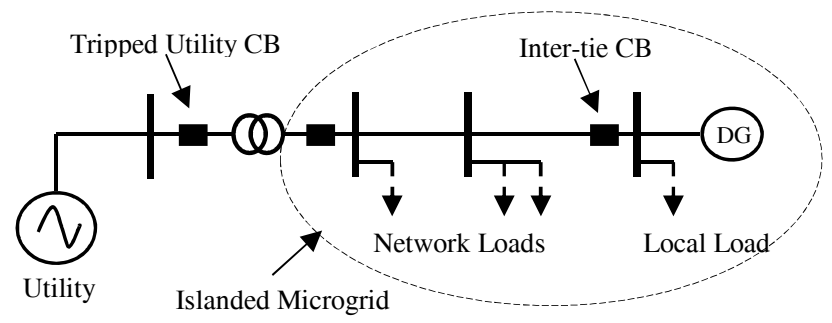

Figure 1. Illustration of micro-grid islanding

Passive islanding detection methods rely on local measurements of critical system parameters (such as- voltage, current, frequency, and phase etc.) and detects islanding events by locating abnormalities in those system parameters. Several passive islanding detection methods have been proposed in literature [4-11], including under voltage and frequency relays, rate-of-change of frequency [4] and rate-ofchange of voltage [5], vector surge relays [6], rate-of-change of phase angle deviation [7], voltage unbalance and total harmonic distortion [8], intelligent based methods [9-10] and wavelet based methods [11] etc. Passive islanding detection methods do not degrade power quality, but these methods suffer from a larger non-detection zone (NDZ). Especially, in presence of power balance in the island (i.e. generation and load are approximately balanced in the islanded system).

This paper proposes a passive islanding detection method for DG units. The proposed method uses a unique set of critical system features derived from voltage and current measurements at target DG location, and utilizes decision tree based classifier for detection and classification of event specific signatures associated with islanding events. The set of critical system features is selected to enhance islanding detection accuracy in the presence of multiple types of DG units, under different system operating and loading conditions. The decision tree classifier is trained with a prescribed system events database obtained via extensive off-line event simulations. Case study has been performed on a microgrid 
model implemented with IEEE 13 node distribution feeder system. A brief description of the proposed methodology and obtained case study results are presented in this paper.

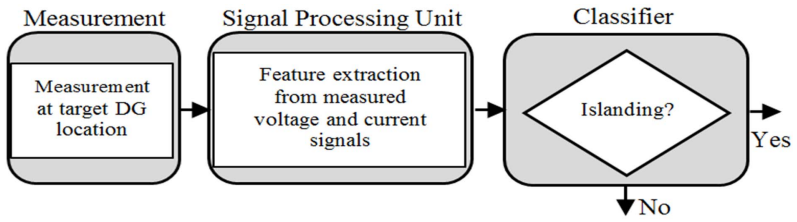

Figure 2. Conceptual model of the proposed islanding detection scheme.

\section{PROPOSED IsLANDING DETECTION METHODOLOGY}

The conceptual model of the proposed islanding detection method is presented in Fig. 2. The proposed method relies on extraction of critical system features from local measurements of voltage and currents, and recognition of event specific signatures associated with these critical features through the application of decision tree (DT) based classifiers for detection of islanding events. DT based methods have been developed for transmission system islanding and other power system monitoring and control problems [12]-[15].

\section{A. Decision Tree Classifier and Performance Indices}

The DTs built in the proposed scheme are classification trees which are built from a training dataset containing ndimensional feature vectors and corresponding class values. The DTs can predict the class of an event (e.g. non-islanding or islanding events) from the n-dimensional feature vector presented to it for the classification [16]. The feature vector consists of critical system attributes whose values are utilized in the classification process.

Classifier accuracy and misclassification rate are commonly used to evaluate the performance of DT classifiers.

$$
\begin{aligned}
& \text { Classifier Accuracy }=\frac{\text { Correctly classified instances }}{\text { Total number of instances }} \\
& \text { Misclassification Rate }=\frac{\text { Misclassified instances }}{\text { Total number of instances }}
\end{aligned}
$$

In assessing the performance of protective devices, dependability index (DI) and security index (SI) is used to quantify the reliability and nuisance tripping tendency. The dependability and security indices are expressed as follows:

$$
\begin{gathered}
D I=\frac{\text { No. of detected islanding events }}{\text { No. of total islanding events }} \\
S I=\frac{\text { No.of detected non }- \text { islanding events }}{\text { No.of total non }- \text { islanding events }}
\end{gathered}
$$

\section{B. Mathematical Modeling}

The concept of the proposed technique can be mathematically illustrated as follows:

$$
\begin{aligned}
& X=\left\langle X_{1}, X_{2}, \ldots \ldots \ldots, X_{n}\right\rangle^{T} \\
& X_{i}=\left\langle x_{1}^{i}, x_{2}^{i}, x_{3}^{i}, \ldots \ldots \ldots, x_{14}^{i}\right\rangle ; i=1,2,3, \ldots \ldots, n \\
& Y=\left\langle y_{1}, y_{2}, \ldots \ldots \ldots, y_{n}\right\rangle^{T}
\end{aligned}
$$

where, $X$ contains the feature vectors of selected features under each of the $\mathrm{n}$ prescribed system events, $X_{i}$ is the feature vector for $i^{\text {th }}$ event and $Y$ is the vector of class values associated with each of the feature vectors, $X_{i}$. With the above definitions, any vector $E$ of n credible system events can be represented as:

$$
E=\left[\begin{array}{ccccc}
x_{1}^{1} & x_{2}^{1} & \ldots & x_{m}^{1} & y^{1} \\
x_{1}^{2} & x_{2}^{2} & \ldots & x_{m}^{2} & y^{2} \\
\vdots & \vdots & & \vdots & \vdots \\
x_{1}^{n} & x_{2}^{n} & \ldots & x_{m}^{n} & y^{n}
\end{array}\right]
$$

\begin{tabular}{|c|c|}
\hline $\mathbf{x}_{1}^{\mathrm{i}}=\Delta \mathbf{V}_{\mathrm{i}}$ & Voltage deviation (V) under $^{\text {th }}{ }^{\text {event; }}$ \\
\hline $\mathbf{x}_{2}^{\mathrm{i}}=(\Delta \mathbf{V} / \Delta \mathbf{t})_{\mathbf{i}}$ & Rate-of-change of voltage (V/sec) under $i^{\text {th }}$ event; \\
\hline $\mathbf{x}_{3}^{\mathbf{i}}=\Delta \mathbf{f}_{\mathbf{i}}$ & Frequency deviation $(\mathrm{Hz})$ under $\mathrm{i}^{\text {th }}$ event; \\
\hline $\mathbf{x}_{\mathbf{4}}^{\mathrm{i}}=(\Delta \mathbf{f} / \Delta \mathbf{t})_{\mathrm{i}}$ & $\begin{array}{l}\text { Rate-of-change of Frequency }(\mathrm{Hz} / \mathrm{sec}) \text { under } i^{\text {th }} \\
\text { event; }\end{array}$ \\
\hline $\mathbf{x}_{5}^{\mathrm{i}}=\mathbf{P}_{\mathrm{i}}$ & $\begin{array}{l}\text { Active power output (Watts) at target DG location } \\
\text { under } i^{\text {th }} \text { event; }\end{array}$ \\
\hline $\mathbf{x}_{6}^{\mathbf{i}}=(\Delta \mathbf{P} / \Delta \mathbf{t})_{i}$ & $\begin{array}{l}\text { Rate-of-change of active power output (Watts/sec) at } \\
\text { target DG location under it }{ }^{\text {th }} \text { event; }\end{array}$ \\
\hline $\mathbf{x}_{7}^{\mathrm{i}}=\mathbf{Q}_{\mathbf{i}}$ & $\begin{array}{l}\text { Reactive power output (VARs) at target DG location } \\
\text { under } i^{\text {th }} \text { event; }\end{array}$ \\
\hline $\mathbf{x}_{\mathbf{8}}^{\mathbf{i}}=(\Delta \mathbf{Q} / \Delta \mathbf{t})_{i}$ & $\begin{array}{l}\text { Rate-of-change of reactive power output (VARs/sec) } \\
\text { at target DG location under } \mathrm{i}^{\text {th }} \text { event; }\end{array}$ \\
\hline $\mathbf{x}_{\mathbf{9}}^{\mathbf{i}}=(\Delta \mathbf{f} / \Delta \mathbf{P})_{\mathbf{i}}$ & $\begin{array}{l}\text { Change in frequency with respect to DG active } \\
\text { power output (Hz/Watts) under } \mathrm{i}^{\text {th }} \text { event; }\end{array}$ \\
\hline $\mathbf{x}_{10}^{\mathrm{i}}=(\Delta \mathbf{V} / \Delta \mathbf{Q})_{\mathbf{i}}$ & $\begin{array}{l}\text { Change in voltage with respect to DG reactive power } \\
\text { output (V/VARs) under } \mathrm{i}^{\text {th }} \text { event; }\end{array}$ \\
\hline $\mathrm{x}_{11}^{\mathrm{i}}=\mathrm{VTHD}_{\mathrm{i}}$ & Total harmonic distortion in voltage under $\mathrm{i}^{\text {th }}$ event; \\
\hline $\mathrm{x}_{12}^{\mathrm{i}}=\mathrm{CTHD}_{\mathrm{i}}$ & Total harmonic distortion in current under $\mathrm{i}^{\text {th }}$ event; \\
\hline $\mathbf{x}_{13}^{\mathrm{i}}=\left(\frac{\Delta\left(\delta_{V}-\delta_{I}\right)}{\Delta \mathrm{t}}\right)$ & $\begin{array}{l}\text { Rate-of-change of phase angle deviation (ROCPAD) } \\
\text { at target DG location under i } \mathrm{i}^{\text {th }} \text { event; }\end{array}$ \\
\hline $\mathbf{x}_{14}^{\mathrm{i}}=\left(\mathbf{V}_{2} / \mathbf{V}_{1}\right)_{\mathrm{i}}$ & $\begin{array}{l}\text { Voltage unbalance at target DG location under } \mathrm{i}^{\text {th }} \\
\text { event. }\end{array}$ \\
\hline
\end{tabular}

The system features for the classification task are selected to include all possible information that could be affected by islanding events and can be measured locally. The following table lists all independent system feature variables used in the proposed method.

TABLE I. CRITICAL FEATURES USED IN ISLANDING DETECTION

\section{Prescribed Events}

Extensive off-line simulations were carried out to capture essential characteristics of the system for generation of the training dataset. The following is a list of some possible events:

- All possible tripping of circuit breakers that might lead to islanding events in microgrids and distribution networks;

- Events that could trip all breakers which can lead to islanding of the DG under study;

- Islanding in EPS transmission network or loss of any distribution line in distribution network;

- Abrupt change in the loading at the target DG location, at PCC bus and in distribution network;

- Capacitor bank switching in the distribution network.

These events have been simulated under various network operating states of area EPS and distribution network or 
microgrid. The operating states include operations with normal, minimum and maximum loading conditions. Different loading conditions at the PCC bus and various operating levels of target DG unit have also been considered in development of the training dataset.

\section{Outline of the Methodology}

The methodology of the proposed decision tree based passive islanding detection approach can be outlined according to the flow diagram presented in Fig. 3.

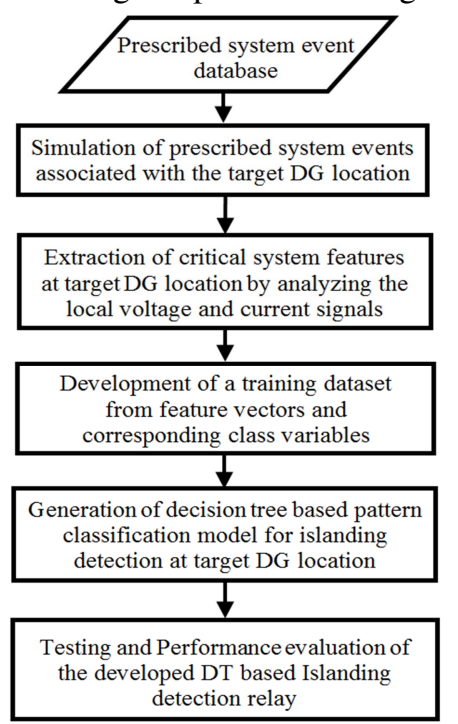

Figure 3. Outline of the proposed islanding detection methodology.

\section{TEST SYSTEM MODELING}

In this paper, a detailed case study on a grid connected microgrid model has been performed in order to evaluate the effectiveness of the proposed method. The test system model is developed using Matlab/Simulink platform. A brief overview of the test system is presented in this section.

\section{A. Main Grid Model}

As described by Table II, the 4-generator, 2-area Kundur system model in [17] is selected as the main grid to be connected with a microgrid model. The system has a relative small size but is able to exhibit typical power system dynamics. Thus, interactions between the main grid and microgrid/DG can be studied.

TABLE II. TWO AREA SYSTEM MODEL OVERVIEW

\begin{tabular}{ccc}
\hline Generators & G-1: 700MW,185MVar & G-3: 719MW, 176MVar \\
& G-2: 700MW, 235MVar & G-4: 700MW, 202MVar \\
\hline Load & Bus-7: 967MW, 100MVar & Bus-9: 1767MW, 100MVar \\
Shunt & Bus-7: 200MVar. & Bus-9: 350MVar. \\
Capacitors & & \\
\hline
\end{tabular}

\section{B. Microgrid Model}

The microgrid model is implemented using IEEE 13 node distribution feeder test system model with two different types of distributed generators (i.e. diesel generator and PV array) and one storage unit (i.e. battery). The 13-node test feeder system is operated at $4.16 \mathrm{kV}$ with unbalanced loads (both single-phase and there-phase loads) and shunt capacitor banks to model a representative distribution system. The microgrid model is connected to area- 2 of the main grid model.

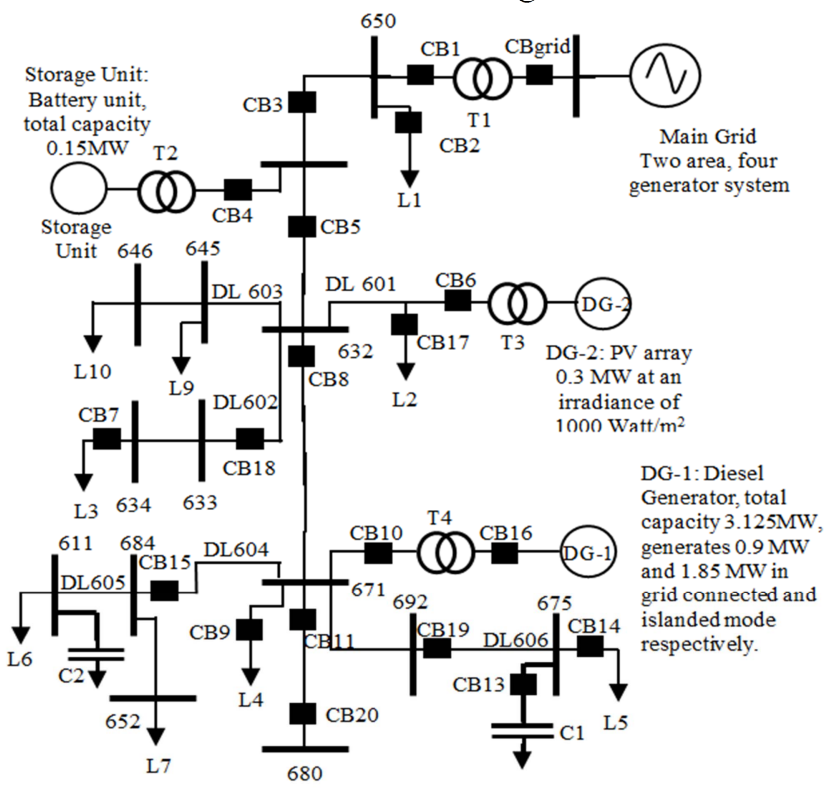

Figure 4. Microgrid model implemented in IEEE 13 node distribution feeder.

\section{CASE STUdY RESUlTS AND Discussions}

In this case study, a total of 486 system events under 27 different system operating conditions (i.e. EPS loading, PCC bus loading, microgrid loading) have been used to generate the measurement database at the target DG location (at the point of common coupling of the DG unit with microgrid). Table III lists all 18 events that have been simulated for each of the 27 different system operation conditions. Critical system features are extracted from obtained measurement dataset and data model for setting the islanding relay at the target DG location (DG-1) is developed.

Based on this data model, decision trees are constructed using the J48 decision tree algorithm. Decision trees were developed using the "Waikato Environment for Knowledge Analysis (WEKA)" [18] data mining platform. Initially, all 14 system features were used in training the DTs and a ranking of the features were generated according to their merit to the classification process. Table IV shows the average merit of each of the system features in DT training.

Two different testing methods -a) 10 -fold cross validation and b) percent split were employed to test the developed decision trees and performances were evaluated based on four indices- classifier accuracy, dependability index, security index and misclassification rate. The 10-fold cross-validation approach divides the entire dataset into 10 equal pieces, and utilizes nine of them for training and one for testing the decision tree in first 10 out of the 11 iterations. In the $11^{\text {th }}$ iteration the entire dataset is entire dataset is treated as the testing data set. From each of the iterations, accuracies are calculated and their average is computed which is the final accuracy result.

The percent split $(80 \%)$ method used in this study divides the entire dataset into a training set and a test set. The training set contains 389 events (262 non-islanding events and 127 
islanding events) and the test set contains 97 events (62 nonislanding events and 35 islanding events). Table $\mathrm{V}$ and Table VI presents the DT performance evaluation results with 10 fold cross validation and percent split methods respectively.

TABLE III. LIST OF SYSTEM EVENTS AND ISLANDING STATUS

\begin{tabular}{lll}
\hline Index & Event description & Status \\
\hline E-1 & Tripping of utility circuit breaker (CBgrid) & Islanding \\
E-2 & Tripping of PCC breaker (CB1) & Islanding \\
E-3 & Tripping of CB1 and CB2 simultaneously & Islanding \\
E-4 & Tripping of CB5 leading to loss of dist. line & Islanding \\
E-5 & Tripping of CB8 leading to loss of dist. line & Islanding \\
E-6 & Tripping of CB6 causing loss of PV unit & Non-islanding \\
E-7 & Tripping of CB4 causing loss of storage unit & Non-islanding \\
E-8 & Tripping of CB3,CB4,CB5; loss of dist. line & Islanding \\
E-9 & Tripping of CB18 leading to loss of dist. line & Non-islanding \\
E-10 & Tripping of CB19 leading to loss of dist. line & Non-islanding \\
E-11a & Sudden load change (increase) at PCC & Non-islanding \\
E-11b & Sudden load change (decrease) at PCC & Non-islanding \\
E-12a & Abrupt load increase at target DG location & Non-islanding \\
E-12b & Abrupt load decrease at target DG location & Non-islanding \\
E-13a & Sudden increase in microgrid loading & Non-islanding \\
E-13b & Sudden decrease in microgrid loading & Non-islanding \\
E-14 & Capacitor bank switching & Non-islanding \\
E-15 & Normal system operation & Non-islanding \\
\hline & &
\end{tabular}

TABLE IV. AVERAGE MERIT OF FEATURES IN DT CLASSIFIER TRAINING

\begin{tabular}{cc||cc}
\hline Feature & Average Merit & Feature & Average Merit \\
\hline $\mathrm{VU}$ & 0.901 & ROCPAD & 0.690 \\
$\Delta \mathrm{V} / \Delta \mathrm{Q}$ & 0.881 & $\Delta \mathrm{P} / \Delta \mathrm{t}$ & 0.68 \\
$\Delta \mathrm{V} / \Delta \mathrm{t}$ & 0.881 & $\mathrm{CTHD}$ & 0.674 \\
$\Delta \mathrm{f} / \Delta \mathrm{t}$ & 0.881 & $\mathrm{VTHD}$ & 0.653 \\
$\Delta \mathrm{f}$ & 0.843 & $\mathrm{P}$ & 0.566 \\
$\Delta \mathrm{V}$ & 0.823 & $\Delta \mathrm{Q} / \Delta \mathrm{t}$ & 0.485 \\
$\Delta \mathrm{f} / \Delta \mathrm{P}$ & 0.691 & $\mathrm{Q}$ & 0.305 \\
\hline
\end{tabular}

The developed DTs were ranked based on their overall classification accuracy, security index (SI), dependability index (DI) and misclassification rate. Test results from cross validation based test method indicate that the best DT obtains an overall classification accuracy of $99.38 \%$ with dependability index (DI) and security index (SI) being 99.38 as well. The classifier depends only on one critical system feature $x_{4}$ (i.e. $\Delta f / \Delta t$, rate of change of frequency) for the classification process. Based on the threshold value associated with the classifier, when, $\Delta f / \Delta t \leq 3.648$, a total of 323 events are classified as non-islanding events out of which 322 are accurately classified instances. When, $\Delta f / \Delta t>3.648,163$ events are classified as islanding events out of which 161 are correctly classified instances. The misclassification rate for the non-islanding event (i.e. rate of false detection) is $0.617 \%$ whereas misclassification rate for islanding events (i.e. rate of false dismissal) is $0.62 \%$. These results are based on the dataset containing 486 events including cases with load and generations within the islanded microgrid are approximately balanced (cases with load and generation mismatches of 5\%, $10 \%$ and $20 \%$ ).

The best performing DT obtained from the second testing method attains a maximum overall accuracy, dependability and security indices of $100 \%$. Since the DT does not misclassify any of the test instances, hence rate of false dismissal and rate of false detection are both zero.
TABLE V. DT PERFORMANCE [10 FOLD CROSS VALIDATION METHOD]

\begin{tabular}{ccccc}
\hline $\begin{array}{c}\text { Critical System } \\
\text { Feature }\end{array}$ & $\begin{array}{c}\text { Classifier } \\
\text { Accuracy }\end{array}$ & DI & SI & $\begin{array}{c}\text { Misclassific } \\
\text { ation Rate }\end{array}$ \\
\hline$\Delta \mathrm{f} / \Delta \mathrm{t}$ & 99.38 & 99.38 & 99.38 & 0.617 \\
$\mathrm{VU}$ & 99.18 & 99.38 & 99.07 & 0.823 \\
$\Delta \mathrm{V} / \Delta \mathrm{Q}$ & 99.18 & 99.38 & 99.07 & 0.823 \\
$\Delta \mathrm{V} / \Delta \mathrm{t}$ & 99.18 & 99.38 & 99.07 & 0.823 \\
$\mathrm{Q}, \Delta \mathrm{Q} / \Delta \mathrm{t}$ & 98.76 & 97.53 & 99.38 & 1.24 \\
$\Delta \mathrm{V}, \mathrm{VTHD}, \Delta \mathrm{P} / \Delta \mathrm{t}$ & 98.35 & 98.15 & 98.45 & 1.65 \\
$\mathrm{CTHD}, \mathrm{P}, \Delta \mathrm{f} / \Delta \mathrm{P}$ & 98.35 & 98.14 & 98.46 & 1.65 \\
$\Delta \mathrm{f}, \Delta \mathrm{f} / \Delta \mathrm{P}, \mathrm{VTHD}$ & 98.14 & 98.76 & 97.84 & 1.86 \\
$\Delta \mathrm{P} / \Delta \mathrm{t}, \mathrm{VTHD}, \Delta \mathrm{f} / \Delta \mathrm{P}$, & 97.53 & 96.29 & 98.15 & 2.47 \\
$\mathrm{ROCPAD}$ & & & & \\
$\mathrm{ROCPAD}, \mathrm{CTHD}, \mathrm{Q}$, & 97.53 & 96.91 & 97.84 & 2.47 \\
$\mathrm{VTHD}, \Delta \mathrm{f} / \Delta \mathrm{P}$ & 96.91 & 96.29 & 97.22 & 3.09 \\
$\Delta \mathrm{f} / \Delta \mathrm{P}, \Delta \mathrm{Q} / \Delta \mathrm{t}, \mathrm{P}$ & 95.26 & 96.91 & 94.44 & 4.74 \\
$\mathrm{P}, \Delta \mathrm{Q} / \Delta \mathrm{t}, \mathrm{Q}$ & 85.60 & 91.35 & 82.72 & 14.4 \\
$\Delta \mathrm{Q} / \Delta \mathrm{t}, \mathrm{Q}$ & & & &
\end{tabular}

TABLE VI. DT PERFORMANCE [PERCENT SPLIT-80\% TEST METHOD]

\begin{tabular}{ccccc}
\hline $\begin{array}{c}\text { Critical System } \\
\text { Feature }\end{array}$ & $\begin{array}{c}\text { Classifier } \\
\text { Accuracy }\end{array}$ & DI & SI & $\begin{array}{c}\text { Misclassific } \\
\text { ation Cost }\end{array}$ \\
\hline$\Delta \mathrm{f} / \Delta \mathrm{t}$ & 100 & 100 & 100 & 0 \\
$\mathrm{VU}$ & 100 & 100 & 100 & 0 \\
$\Delta \mathrm{V} / \Delta \mathrm{Q}$ & 100 & 100 & 100 & 0 \\
$\Delta \mathrm{V} / \Delta \mathrm{t}$ & 100 & 100 & 100 & 0 \\
$\Delta \mathrm{V}, \mathrm{VTHD}, \Delta \mathrm{P} / \Delta \mathrm{t}$ & 98.97 & 100 & 98.36 & 1.03 \\
$\Delta \mathrm{f}, \Delta \mathrm{f} / \Delta \mathrm{P}, \mathrm{VTHD}$ & 98.97 & 100 & 98.36 & 1.03 \\
$\mathrm{VTHD}, \Delta \mathrm{f} / \Delta \mathrm{P}, \mathrm{CTHD}$, & 97.94 & 97.15 & 98.35 & 2.06 \\
$\mathrm{Q}, \Delta \mathrm{Q} / \Delta \mathrm{t}$ & 97.94 & 97.14 & 98.39 & 2.06 \\
$\Delta \mathrm{f} / \Delta \mathrm{P}, \Delta \mathrm{Q} / \Delta \mathrm{t}, \mathrm{P}$ & 96.91 & 100 & 95.16 & 3.09 \\
$\mathrm{CTHD}, \mathrm{P}, \Delta \mathrm{f} / \Delta \mathrm{P}$ & 96.91 & 100 & 95.16 & 3.09 \\
$\mathrm{ROCPAD}, \mathrm{CTHD}, \mathrm{Q}$, & 94.85 & 94.25 & 95.16 & 5.15 \\
$\mathrm{VTHD}, \Delta \mathrm{f} / \Delta \mathrm{P}$ & 94.84 & 91.45 & 96.77 & 5.16 \\
$\mathrm{P}, \Delta \mathrm{Q} / \Delta \mathrm{t}, \mathrm{Q}$ & 82.47 & 94.29 & 75.81 & 17.53 \\
\hline $\mathrm{P} / \Delta \mathrm{t}, \mathrm{VTHD}, \Delta \mathrm{f} / \Delta \mathrm{P}$, & & & & \\
$\mathrm{ROCPAD}$ & & &
\end{tabular}

However, accuracy of DTs heavily depends on the dataset used in training and testing. Misclassification in DTs can be caused by a wide variety of reasons. If the dataset used in training have a greater similarity with the one used for testing, then resulting DTs have better prediction accuracies. Otherwise, a high accuracy in prediction cannot be guaranteed. Performances of DTs can be enhanced with periodically including new and unknown system states in the training dataset. Moreover, overall performance of DTs in the proposed method also depends on the set of critical features selected. Tables VII and VIII present the performance of the DTs for balanced system operating conditions (i.e. relatively smaller mismatch between generation and load). The results indicate that the best DT demonstrates a high accuracy.

TABLE VII. DT CLASSIFIER PERFORMANCE EVALUATION UNDER BALANCED OPERATING CONDITIONS [10-FOLD CROSS VALIDATION]

\begin{tabular}{|c|c|c||c|c|}
\cline { 2 - 5 } \multicolumn{1}{c|}{} & \multicolumn{2}{c||}{ Islanding Cases } & \multicolumn{2}{c|}{ Non-Islanding Cases } \\
\cline { 2 - 5 } \multicolumn{1}{c|}{} & $\begin{array}{c}\text { Total } \\
\text { Cases }\end{array}$ & $\begin{array}{c}\text { Correctly } \\
\text { Classified }\end{array}$ & $\begin{array}{c}\text { Total } \\
\text { Cases }\end{array}$ & $\begin{array}{c}\text { Correctly } \\
\text { Classified }\end{array}$ \\
\hline DT-1 & 36 & $36(100 \%)$ & 72 & $71(98.61 \%)$ \\
\hline DT-2 & 36 & $36(100 \%)$ & 72 & $71(98.61 \%)$ \\
\hline DT-3 & 36 & $36(100 \%)$ & 72 & $71(98.61 \%)$ \\
\hline DT-4 & 36 & $36(100 \%)$ & 72 & $70(97.22 \%)$ \\
\hline DT-5 & 36 & $35(97.22 \%)$ & 72 & $71(98.61 \%)$ \\
\hline
\end{tabular}


TABLE VIII. DT CLASSIFIER PERFORMANCE EVALUATION UNDER BALANCED OPERATING CONDITIONS [PERCENT SPLIT-80\%]

\begin{tabular}{|c|c|c||c|c|}
\cline { 2 - 5 } \multicolumn{1}{c|}{} & \multicolumn{2}{c||}{ Islanding Cases } & \multicolumn{2}{c|}{ Non-Islanding Cases } \\
\cline { 2 - 5 } \multicolumn{1}{c|}{} & $\begin{array}{c}\text { Total } \\
\text { Cases }\end{array}$ & $\begin{array}{c}\text { Correctly } \\
\text { Classified }\end{array}$ & $\begin{array}{c}\text { Total } \\
\text { Cases }\end{array}$ & $\begin{array}{c}\text { Correctly } \\
\text { Classified }\end{array}$ \\
\hline DT-1 & 18 & $18(100 \%)$ & 36 & $36(100 \%)$ \\
\hline DT-2 & 18 & $18(100 \%)$ & 36 & $36(100 \%)$ \\
\hline DT-3 & 18 & $18(100 \%)$ & 36 & $36(100 \%)$ \\
\hline DT-4 & 18 & $18(100 \%)$ & 36 & $36(100 \%)$ \\
\hline DT-5 & 18 & $18(100 \%)$ & 36 & $36(100 \%)$ \\
\hline
\end{tabular}

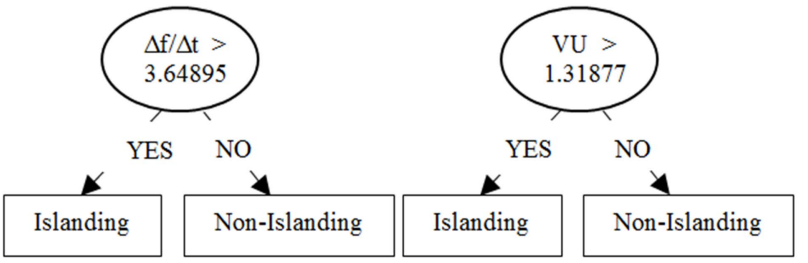

Figure 5. Decision tree structures based on system features $\Delta \mathrm{f} / \Delta \mathrm{t}$ and $\Delta \mathrm{U}$. Both of the trees have one internal node and two terminal nodes.

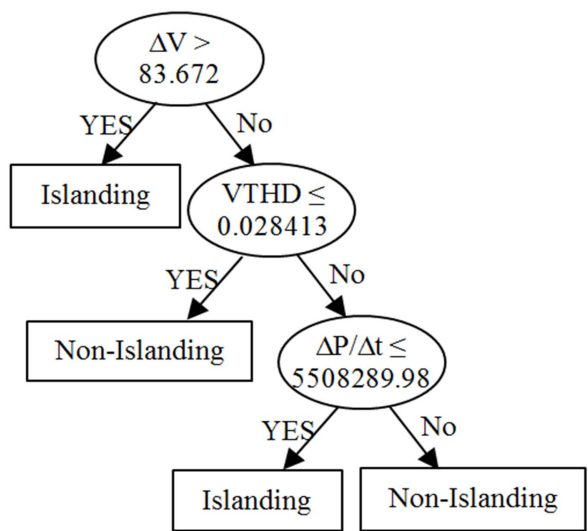

Figure 6. Decision tree structure based on system features $\Delta \mathrm{V}$, VTHD and $\Delta \mathrm{P} / \Delta \mathrm{t}$. The tree has three internal nodes and four terminal nodes.

The proposed DT based islanding relays from both testing methods show similar response times. The maximum and minimum response times observed are 0.0232 seconds (DT4) and 0.0204 seconds (DT2) respectively.

Multiple optimal DTs trained with combinations of different system features can be utilized to improve the reliability and prediction accuracy of the proposed islanding detection method. In this approach, DTs satisfying a desired performance threshold can be incorporated in the detection process instead of relying on the best performing DT since cases misclassified by the DT can be accurately classified by other DTs employing a different combination of system features for classification.

\section{CONCLUSION}

A passive islanding detection technique for DG islanding detection is proposed in this paper. The proposed method utilizes a comprehensive set of critical system features and employs decision tree based classifiers for recognition and classification of underlying pattern of different types of system events for islanding detection. Case studies on grid connected microgrid model consisting of multiple DGs and storage unit indicate that the proposed method is capable of detecting islanding events with a high degree of accuracy in microgrids or distribution networks under different system operational and loading states. Furthermore, the classification accuracy and robustness of the proposed method can be enhanced by adaptively expanding the training dataset.

\section{REFERENCES}

[1] IEEE Standard for Interconnecting Distributed Resources With Electric Power Systems, IEEE Std. 1547-2003, 2003.

[2] R. A. Walling and N. W. Miller, "Distributed generation islanding implications on power system dynamic performance," in Proc. 2002 IEEE Power Eng. Soc. Summer Meeting, vol.1, pp.92-96.

[3] H. G. Far, A. J. Rodolak, and G. Joos,"Synchronous distributed generation islanding protection using intelligent relays," IEEE Trans. Smart Grid, vol. 3, no.4, pp. 1695-1703, Dec.2012.

[4] W. Freitas, et al, "Comparative analysis between ROCOF and vector surge relays for distributed generation applications," IEEE Trans. Power Del., vol. 20, no. 2, pt.. 2, pp. 1315-1324, Apr. 2005.

[5] P. Mahat,, Z. Chen, and B. B. Jensen, "A hybrid islanding detection technique using rate of change of voltage and real power shift," IEEE Trans. Power Delivery, vol. 24, no. 2, pp. 764-771, Apr. 2009.

[6] W. Freitas, et al, "A practical method for assessing the effectiveness of vector surge relays for distributed generation applications," IEEE Trans. power Delivery, vol. 20, no. 1, pp. 57-63, Jan. 2005.

[7] A. Samui and S. R. Samantaray, "Assessment of ROCPAD relays for islanding detection in distributed generation," IEEE Trans. Smart Grid, vol. 2, no. 2, pp. 391-398, Jun. 2011.

[8] S. I. Jang, et al, "An islanding detection method for distributed generation using voltage unbalance and total harmonic distortion of current," IEEE Trans. Power Delivery, vol. 19, no. 2, pp. 745-752, Apr. 2004.

[9] K. El-Arroudi, G. Joos, I. Kamwa, and D. T. McGillis, "Intelligent based approach to islanding detection in distributed generation," IEEE Trans. Power Delivery, vol. 22, no. 2, Apr. 2007.

[10] K. El-Arroudi, G Joos, and I. Kamwa, "Data mining approach to threshold setting of islanding relays in distributed generation," IEEE Trans. Power Systems, vol.22, no. 3, Aug. 2007.

[11] N. W. A. Lidula and A. D. Rajapakse, "A pattern recognition approach for detecting power islands using transient signals- Part I: design and implementation, " IEEE Trans. Power Delivery, vol. 25, no. 4, pp. 3070-3077, Oct. 2008.

[12] R. Diao, V. Vittal, K. Sun, et tal, "Decision Tree Assisted Controlled Islanding for Preventing Cascading Events", IEEE PES Power Systems Conference \& Exposition, Seattle, March 15-18, 2009

[13] C. Liu, K. Sun, et al, "A Systematic Approach for Dynamic Security Assessment and the Corresponding Preventive Control Scheme Based on Decision Trees", IEEE Trans. Power Systems, vol. 29, No. 2, pp 717-730, March 2014

[14] K. Sun, et al, "An Online Dynamic Security Assessment Scheme using Phasor Measurements and Decision Trees", IEEE Trans. Power Systems, vol. 22, pp. 1935-1943, Nov 2007.

[15] R. Diao, K. Sun, V. Vittal, et tal, "Decision Tree-Based Online Voltage Security Assessment Using PMU Measurements", IEEE Trans. Power Systems, vol. 24, pp.832-839, May 2009.

[16] S. R. Safavian, et al, "A survey of decision tree classifier methodology," IEEE Trans. Syst. Man Cybern., vol. 21, no. 3, pp. 660674, June 1991.

[17] Prabha Kundur, Power System Stability and Control. New York: McGraw-Hill Professional, 1994, p. 813.

[18] I. Witten, E. Frank, Data Mining: practical Machine Learning Tools and Techniques. Morgan Kaufmann Publishers, 2011, pp. 365-483. 